\title{
Earthquake Monitoring Network of Erzurum: ATANET
}

\author{
Caglar Ozer (Corresponding author) \\ Earthquake Research Centre, Ataturk University \\ PO box 25240, Erzurum, Turkey \\ E-mail: caglarozer@atauni.edu.tr \\ Mustafa Engin Kocadagistan \\ Metallurgical and Materials Engineering, Ataturk University \\ PO box 25240, Erzurum, Turkey \\ E-mail: mengink@atauni.edu.tr \\ Sukran Perk \\ Earthquake Research Centre, Ataturk University \\ PO box 25240, Erzurum, Turkey \\ E-mail: sukran.perk@atauni.edu.tr
}

This work was supported by Research Fund of the Ataturk University. Project Number: FAD-2019-7180.

\begin{abstract}
The main aim of this study is to introduce Ataturk University Earthquake Research Center and to announce the studies carried out to the scientific world. Erzurum Earthquake Monitoring Network (ATANET), which consists of 16 weak ground motion sensors established with the facilities of Ataturk University Earthquake Research Center, is an important institution where routine analysis of earthquakes occurred in the Eastern Anatolia region. The Ataturk University Earthquake Research Center, which plays an active role in the Eastern Anatolia Region, conducts earthquake analyzes in the area between $38.00^{\circ}-42.00^{\circ} \mathrm{N}$ latitudes and $38.00^{\circ}-44.50^{\circ} \mathrm{E}$ longitudes surrounding the main tectonic elements that produce earthquake. In this study, 668 earthquakes recorded by ATANET between 2014-2015 were analyzed. The focal depths of most earthquakes ranging in magnitude from 1.0 to 5.0 are concentrated in the first $25 \mathrm{~km}$. It was determined that most of the earthquakes were clustered in Askale fault and Horasan-Senkaya fault zone. According to the fault plane results, it is observed that the region is dominated by faults, which are predominantly strike slip component and reverse faults. The results support the known tectonic structure in the Eastern Anatolia Region under the influence of compression tectonic regime.
\end{abstract}

Keywords: Ataturk University, ATANET, earthquake, tectonic.

DOI: $10.7176 / \mathrm{JSTR} / 5-8-04$

\section{Erzurum Deprem İzleme A ̆ğ: ATANET}

Özet

Atatürk Üniversitesi Deprem Araştırma Merkezinin tanıtılması ve yürüttüğü çalışmaların bilim dünyası ile paylaş̧lması bu çalışmanın ana hedefidir. Atatürk Üniversitesi Deprem Araştırma Merkezinin imkanları ile kurulmuş 16 adet zayıf yer hareketi sensörlerinden oluşan Erzurum Deprem İzleme Ağ1 (ATANET), Doğu Anadolu bölgesinde meydana gelen depremlerin rutin analizlerinin yapıldığı önemli bir araştırma merkezidir. Doğu Anadolu Bölgesinde etkin bir rol üstlenen Atatürk Üniversitesi Deprem Araştırma Merkezi, deprem üreten ana tektonik unsurları çevreleyecek şekilde $38.00^{\circ}-42.00^{\circ} \mathrm{K}$ enlemleri ile $38.00^{\circ}-44.50^{\circ} \mathrm{D}$ boylamları arasında kalan alanda faaliyet göstermektedir. Bu çalışmada ATANET tarafindan 2014-2015 yılları arasında kayıt edilen 668 deprem analiz edilmiştir. Büyüklükleri 1.0 ile 5.0 arasında değişen depremlerin birçoğunun odak derinlikleri ilk $25 \mathrm{~km}$ 'de yoğunlaşmaktadır. Depremlerin büyük çoğunluğunun Aşkale fayında ve Horasan-Şenkaya fay zonunda kümelendiği 
belirlenmiştir. Fay düzlemi sonuçlarına göre, bölgenin özellikle baskın doğrultu atım bileşeni olan faylar ve ters faylar tarafından domine edildiği gözlenmiştir. Elde edilen çözümler, sıkışma tektoniği rejimi etkisi altındaki Doğu Anadolu Bölgesindeki bilinen tektonik yapıyı desteklemektedir.

Anahtar Kelimeler: Atatürk Üniversitesi, ATANET, deprem, tektonik

\section{Giris}

1989 yılında kurulan Atatürk Üniversitesi Deprem Araştırma Merkezi (ATA-DAM) tarafindan işletilen toplam 16 adet zayıf yer hareketi deprem istasyonundan oluşan Erzurum Deprem İzleme Ağı (ATANET), Doğu Anadolu bölgesinde ileri düzey sismoloji araştırmaların yapılmasına imkân sağlamaktadır (Çizelge 1). 2013 yılında Afet ve Acil Durum Yönetimi Başkanlığı (AFAD) ile yapılan protokol ile AFAD ile ATA-DAM arasında deprem verileri paylaşlarak toplam 31 adet istasyon verisi ATA-DAM'e gelmektedir. Ayrıca beş istasyon verisi Uluslararası Sismoloji merkezi (ISC) ile paylaşılmakta olup, ISC tarafindan da merkezimize Gürcistan, İran ve Azerbaycan'da bulunan bazı deprem istasyonların verisi aktarılmaktadır. Böylelikle Doğu Anadolu Bölgesinde etkin bir rol üstlenen ATA-DAM, deprem üreten ana tektonik unsurları çevreleyecek şekilde $38.00^{\circ}-42.00^{\circ} \mathrm{K}$ enlemleri ile $38.00^{\circ}-44.50^{\circ} \mathrm{D}$ boylamları arasında kalan alanda rutin deprem analizlerini yürütmektedir (Şekil 1). Depremlerin kesintisiz, eş zamanlı olarak gözlenmesi ve kayıtlarının alınması deprem sonuçlarının kontrol altına alınabilmesi açısından önemlidir. Erzurum ve Doğu Anadolu bölgesinde yapılan sismik tehlike çalışmaları ATA-DAM çalışma alanının büyük bir risk altında olduğunu göstermektedir (Bayrak vd. 2013, Bayrak vd. 2015, Bayrak, 2019). Ayrıca deprem parametrelerinin doğru şekilde belirlenmesi afet yönetimi ve sismik risk açısından da büyük önem arz etmektedir. Erzurum şehir merkezi ve yakın çevresinde her gün 10'un üzerinde deprem meydana gelmektedir. Bu depremlerin parametrelerinin güvenilir olarak belirlenmesi, lokasyonlarının tespit edilmesi ve ileri bilimsel araştırmaların yapılması ATANET sismik ağı ile mümkün olmaktadır. Bu zayıf yer hareketi ağı, Erzurum ve çevresinde geçmişte meydana gelen depremler dikkate alınarak, Erzurum ve çevre illerini kapsayacak şekilde geliştirilmiş ve bu ağda bulunan sismik istasyonlardan sürekli veri alınabilir duruma getirilmiştir. ATANET sismik istasyonlarından gelen veriler ATA-DAM' da eş zamanlı kaydedilip değerlendirilmektedir.

Çizelge 1. ATANET deprem istasyonlarına ait konum ve cihaz bilgileri

\begin{tabular}{|c|c|c|c|c|c|c|}
\hline No & $\begin{array}{c}\text { İstasyon } \\
\text { Kodu }\end{array}$ & $\begin{array}{c}\text { Boylam } \\
\mathbf{(}^{\circ}\end{array}$ & $\begin{array}{c}\text { Eylem } \\
\mathbf{(}^{\circ}\end{array}$ & $\begin{array}{c}\text { Yükseklik } \\
(\mathbf{m e t r e})\end{array}$ & Cihaz & İletişim \\
\hline 1 & AKDA & 41.3636 & 40.1035 & 1883 & CMG-3T & GPRS Modem \\
\hline 2 & ATA5 & 41.2447 & 40.9046 & 1950 & CMG- 3T & Kablolu İnternet \\
\hline 3 & EAK & 43.6069 & 40.6862 & 1613 & CMG- 3T & Uydu \\
\hline 4 & EATA & 42.2950 & 39.5173 & 2770 & CMG- 6TD & Uydu \\
\hline 5 & ECAT & 40.9742 & 39.6062 & 1910 & CMG- 3T & Uydu \\
\hline 6 & EDAM & 41.2587 & 39.8955 & 1950 & CMG-5TD & Kablolu İnternet \\
\hline 7 & EJDE & 41.3035 & 39.8330 & 3185 & CMG-6TD & GPRS Modem \\
\hline 8 & EKAR & 42.0640 & 39.2559 & 2129 & CMG- 3T & Uydu \\
\hline 9 & EMRE & 40.9762 & 40.0302 & 2071 & CMG-6TD & GPRS Modem \\
\hline 10 & EPOS & 42.7279 & 41.5035 & 1583 & CMG- 3T & Kablolu İnternet \\
\hline 11 & ERZM & 41.3622 & 39.9044 & 2397 & Geotech S13 & GPRS Modem \\
\hline 12 & TEKE & 41.1370 & 39.7940 & 2128 & CMG-6TD & GPRS Modem \\
\hline 13 & EUZM & 39.6977 & 39.7075 & 1250 & CMG- 3T & GPRS Modem \\
\hline 14 & KONA & 41.2280 & 39.7792 & 3099 & CMG-6TD & Kablolu İnternet \\
\hline 15 & KRIK & 40.9271 & 40.3374 & 2050 & CMG- 3T & GPRS Modem \\
\hline 16 & OLTU & 41.9735 & 40.5461 & 1400 & CMG-6TD & Uydu \\
\hline
\end{tabular}



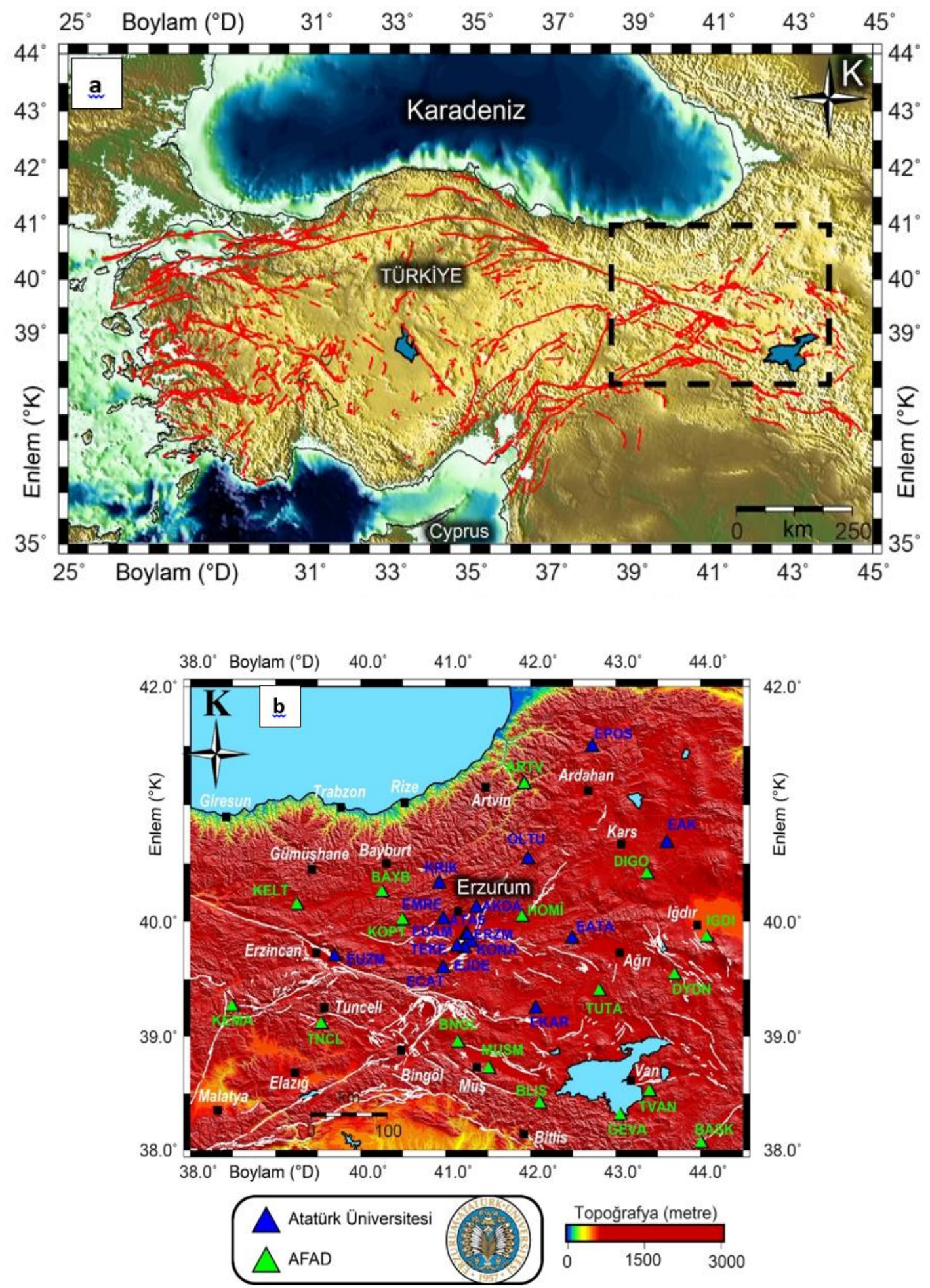

Şekil 1.a. Türkiye tektonik haritası. Şekil 1.b.Erzurum'un yerel sismik ağı olan ATANET ve AFAD deprem kayıtçılarının dağılımı. Mavi üçgenler ATA-DAM tarafindan kurulan kayıtç̧ları simgelerken, yeşil üçgenler AFAD tarafından kurulan sensörleri göstermektedir. Fay bilgileri Maden Tetkik ve Arama (MTA) çizim editöründen sayısallaştırılmıştır (Emre vd. 2013 ve Emre vd. 2018). 
ATANET, bir zayıf yer hareketi deprem istasyon ağıdır ve Erzurum ve yakın çevresinde deprem parametrelerinin ve bölgenin mevcut tektonik yapısını aydınlatmaya yönelik araştırmalar yapmaktadır. Ayrıca bu yerel ağ kullanılarak temel sismolojik araştırmalar (Havskov et al. 2016), zemin araştırmaları (Ozer, 2019a, b) ve tomografik çalışmalar (Ozer vd. 2019, Ozer ve Ozyazıcıŏlu, 2019) yürütülmektedir. ATANET yaklaşık $221,778 \mathrm{~km}^{2}$ alana yayılmaktadır ve AFAD ile yapılan protokol ile paylaşılan veriler 1şığında ATA-DAM bu alanda söz sahibidir. Tüm deprem istasyonların altyapısı uluslararası standartlar gözetilerek kurulmuştur. Erzurum ve çevresinde -40 dereceye ulaşan soğuklara karşı özel galvaniz kulübeler ve özel güneş panelleri kullanılmıştır. Sensörler 24-bit sayısallaştırıcı ve GPS zaman algılayıcısına sahip olup saniyede 100 örnek almaktadır. Kesintisiz gözlem Erzurum-ATADAM ve Ankara-AFAD sistem laboratuvarlarında 7/24 prensibinde yapılmaktadır (Şekil 2). ATANET'de bulunan sismik istasyonlarının lokasyonları belirlenirken; gürültüden uzak ve sağlam zemin üzerinde olması, elektrik ve telefon hattının bulunması, GAP (azimut) gibi faktörler dikkate alınarak belirlenmiştir. ATANET kapsamındaki tüm istasyonlarda veri iletimi; uydu, ADSL (kablolu internet) ya da GPRS modemler ile gerçekleştirilmektedir. Bu istasyonlardan GCF (Güralp Compressed Format) uzantılı kayıtlar AFAD'a eş zamanlı gönderilmektedir. AFAD üzerinden de paylaşılan veriler merkezimize SeisComP yazılımı (https:/www.seiscomp3.org/) ile ATA-DAM'a mseed formatında aktarılmaktadır (Şekil 3). 24 saat takip edilen deprem verileri ilk etapta SEISAN yazılımı (Havskov ve Ottemoller, 1999) aracılığıyla konumları belirlenip, deprem parametreleri tespit edilmektedir.

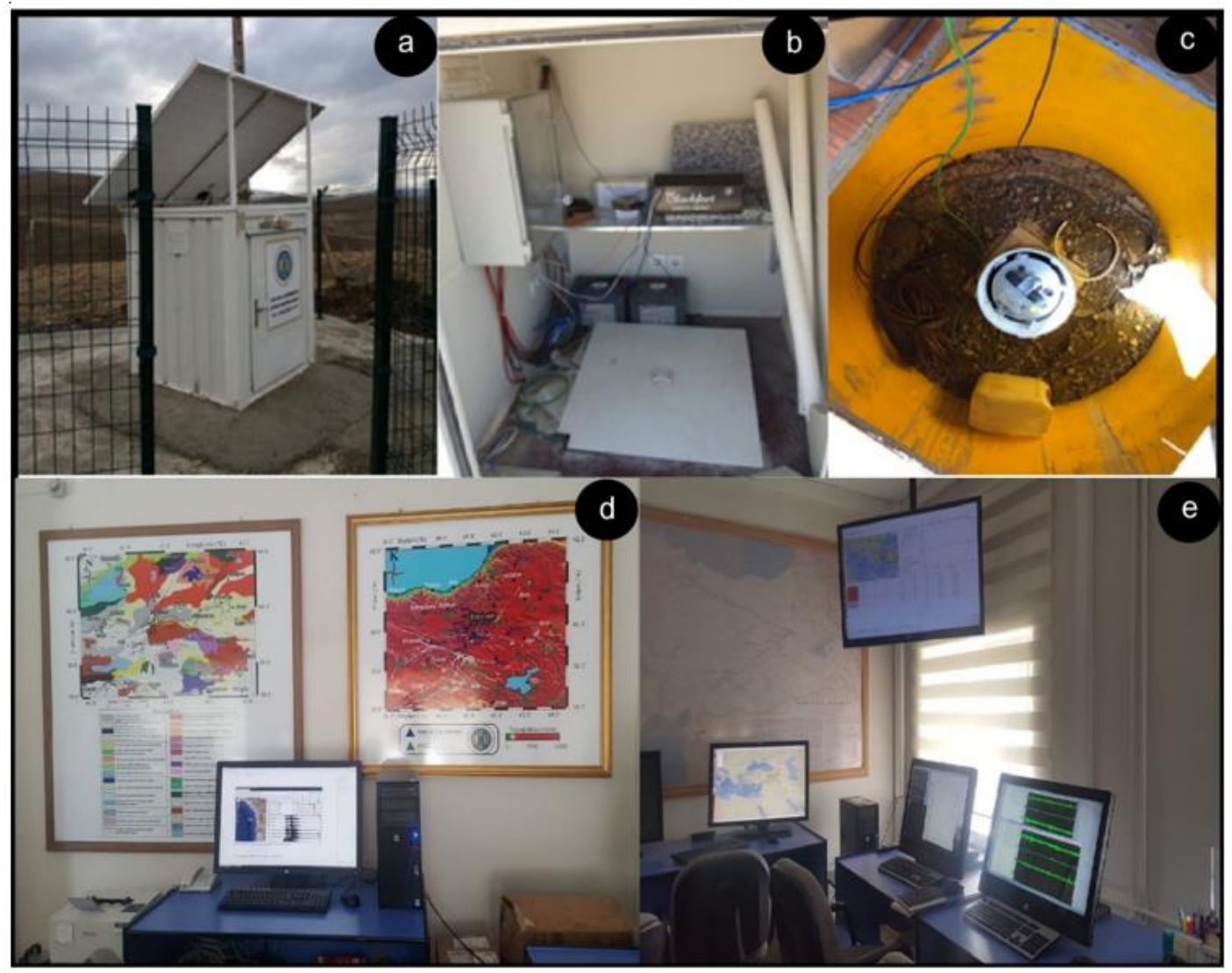

Şekil 2. ATANET ve ATA-DAM'a ait görseller. a. ETEKE istasyonunun uzaktan görünümü. b. ETEKE istasyonunun iç görünümü. c. ETEKE istasyonuna ait sensörün görünümü. d. ATA-DAM sistem odasının görünümü. e. ATANET veri işlem bilgisayarlarının görünümü 


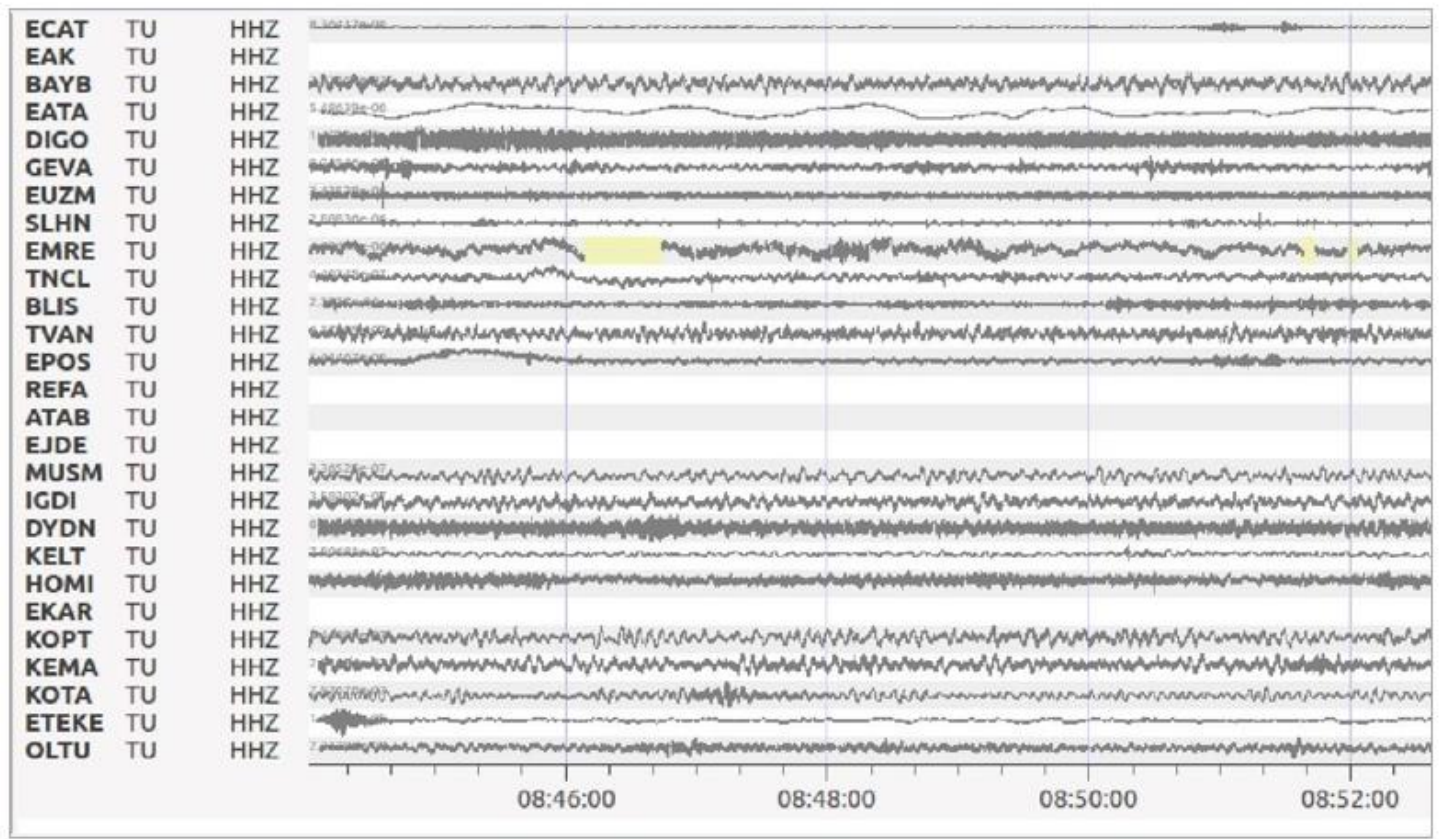

Şekil 3. Üç bileșenli deprem istasyonlardan gelen eș-zamanlı verilerin, veri-ișlem odasındaki SeisComP yazılımına ait temsili ekran görüntüsü

Doğu Anadolu Bölgesi, Arap-Avrasya levhasının yakınlaşmasının (McQuarrie vd., 2003) gerçekleștiği alanda yer aldığından sismik olarak aktif bir bölgededir. Bölge önemli fay sistemlerini içerir. Yüzyıllar boyunca yıkıcı büyük depremlerin meydana geldiği Kuzey Anadolu Fay Zonu (KAFZ) ve Doğu Anadolu Fay Zonu (DAFZ) bu tektonik birimlerin en önemli unsurlarıdır (Sengor, 1979; Orgulu vd. 2003; Fichtner vd. 2013; Vanacore vd. 2013; Simao vd. 2016). Binalarda hasarlara ve ölümlere yol açan 27 Aralık 1939 Erzincan ve 23 Ekim 2011 Van depremleri (sırasıly, $\mathrm{Mw}=7.8$ ve $\mathrm{Mw}=7.2$ ) bu bölge içinde meydana gelmiştir. Türkiye'de aletsel dönemde kaydedilen en büyük deprem olan 1939 Erzincan depremi aktif bir sağ yanal atımlı fay olan KAFZ üzerinde gerçekleşmiștir. Bu deprem, $360 \mathrm{~km}$ uzunluğundaki bir yüzeyde yırtılmaya neden olmuştur (Barka, 1996). 23 Ekim 2011 Van depreminde ise yırtığın 8-9 km ve kayma derinliğinin $14 \mathrm{~km}$ olması depremin yarattı̆̆ı etkiyi açıkça göstermektedir (Elliott vd. 2013).

Tarihsel dönemde (1900'lü yılların öncesi) Erzurum ve yakın çevresinde meydana gelmiş depremler incelendiğinde on şiddetine kadar depremler rapor edilmiştir (Çizelge 2). Aletsel dönemde ise Erzurum il sinırlarında meydana gelmiș en büyük depremler kronolojik sırayla 1901 Pasinler $(\mathrm{M}=6.1)$, 1906 Oltu ( $M=6.0), 1924$ yllı Köprüköy ( $M=6.8)$ ve 1983 yllı Şenkaya-Horasan (M=6.6) depremleridir (Çizelge 3). Erzurum Havzası, Doğu Anadolu'daki sismik olarak oldukça aktif olan ve 1 Ocak 2019 tarihinde yürürlüğe giren AFAD tarafindan hazırlanan deprem tehlike haritasında yüksek ivme değerlerine $(>0.5 \mathrm{~g})$ sahip olan bir bölgedir. 25 Mart 2004 tarihinde büyüklüğü 5.1 ve 28 Mart 2004 tarihinde büyüklüğü 5.3 olan iki deprem meydana gelmiştir. Orta büyüklük olarak tanımlanan bu depremler sol yönlü doğrultu atımlı olan Aşkale Fay Zonunda gerçekleşmiştir. Öte yandan Horasan-Şenkaya Fay Zonu; birbirine paralel KKD-GGB ve KB-GD gidișli ve uzunluğu 10 km'ye kadar uzanan kırıklardan oluşmaktadır. Sol yönlü doğrultu atımlı fay olan Horasan-Şenkaya Fay Zonu, 30 Ekim 1983 tarihinde, Mw=6.6 büyüklüğ̈̈nde bir deprem üretmiş̧tir. Bu deprem sonrasında 1.155 kişi hayatını kaybetmiş ve 537 kişi yaralanmış, 3.241 konut ağır, 3.000 konut orta ve 4.000 konut hafif hasar görmüş, 30.000'i aşkın hayvan telef olmuştur (AFAD Deprem Raporu, 2018). 
Çizelge 2. Erzurum ve çevresini etkileyen tarihsel depremlerin listesi (AFAD Deprem Daire Başkanlığı verilerinden derlenmiștir)

\begin{tabular}{|l|l|l|l|l|}
\hline Tarih & Enlem & Boylam & Şiddet & Yer \\
\hline M.S. 1268 & 40.00 & 40.00 & IX & Erzincan, Erzurum \\
\hline M.S. 1458 & 40.00 & 40.00 & X & Erzincan, Erzurum \\
\hline M.S. 1482 & 40.00 & 40.00 & IX & Erzincan, Erzurum \\
\hline M.S. 1584 & 40.00 & 40.00 & IX & Erzincan, Erzurum \\
\hline M.S. 1659 & 40.00 & 41.00 & VI & Erzurum \\
\hline M.S. 1781 & 40.00 & 41.00 & VII & Erzurum \\
\hline M.S. 1784 & 40.00 & 40.00 & VIII & Erzincan, Pülümür, Erzurum \\
\hline M.S. 1790 & 40.00 & 41.00 & VIII & Erzurum \\
\hline M.S. 1794 & 40.00 & 41.00 & VI & Erzurum \\
\hline M.S. 1844 & 40.00 & 41.00 & VII & Erzurum \\
\hline M.S. 1850 & 40.00 & 41.00 & VII & Erzurum \\
\hline M.S. 1852 & 40.00 & 41.00 & IX & Erzurum \\
\hline M.S. 1852 & 40.00 & 41.00 & VI & Erzurum \\
\hline M.S. 1859 & 40.00 & 41.00 & VII & Erzurum \\
\hline M.S. 1859 & 40.00 & 41.00 & IX & Erzurum \\
\hline M.S. 1859 & 40.00 & 42.00 & VIII & Pasinler - Erzurum \\
\hline M.S. 1860 & 40.00 & 41.00 & VII & Erzurum \\
\hline M.S. 1866 & 40.00 & 41.00 & VIII & Erzurum \\
\hline M.S. 1868 & 41.00 & 44.00 & VIII & Kars, Erzurum, Ardahan, Tiflis \\
\hline M.S. 1868 & 40.00 & 42.00 & VIII & Pasinler - Erzurum \\
\hline M.S. 1868 & 40.00 & 42.00 & IX & Erzurum, Kars \\
\hline M.S. 1875 & 40.00 & 41.00 & X & Erzurum \\
\hline M.S. 1877 & 40.00 & 41.00 & VI & Erzurum \\
\hline M.S. 1886 & 40.00 & 41.00 & VI & Erzurum \\
\hline
\end{tabular}

Çizelge 3. Erzurum ve çevresini etkileyen aletsel deprem listesi (M>6.0) (AFAD Deprem Daire Başkanlığ 1 verilerinden derlenmiştir)

\begin{tabular}{|l|l|l|l|l|l|l|l|}
\hline Oluş Tarihi & $\begin{array}{c}\text { Oluş } \\
\text { Zamanı }\end{array}$ & Enlem & Boylam & $\begin{array}{c}\text { Derinlik } \\
(\mathbf{k m})\end{array}$ & Tür & Büyüklük & \multicolumn{1}{|c|}{ Yer } \\
\hline $30 / 10 / 1983$ & $04: 12: 29$ & 40.331 & 42.173 & 15 & Mw & 6.6 & $\begin{array}{l}\text { Senkaya, Narman, } \\
\text { Horasan-Erzurum }\end{array}$ \\
\hline $20 / 08 / 1966$ & $11: 59: 09$ & 39.420 & 40.980 & 14 & Ms & 6.2 & Karlıva-Bingö1 \\
\hline $19 / 08 / 1966$ & $12: 22: 11$ & 39.170 & 41.560 & 26 & Ms & 6.9 & Varto-Muş \\
\hline $17 / 08 / 1949$ & $18: 44: 20$ & 39.570 & 40.620 & 40 & Ms & 6.7 & Tercan-Erzincan \\
\hline $13 / 09 / 1924$ & $14: 34: 14$ & 39.960 & 41.940 & 10 & Ms & 6.8 & $\begin{array}{l}\text { Köprüköy- } \\
\text { Erzurum }\end{array}$ \\
\hline $28 / 12 / 1906$ & $00: 00: 00$ & 40.500 & 42.000 & 30 & Ms & 6.0 & Oltu-Erzurum \\
\hline $28 / 04 / 1903$ & $23: 46: 00$ & 39.100 & 42.500 & 30 & Ms & 6.3 & Malazgirt-Muş \\
\hline $08 / 11 / 1901$ & $10: 18: 00$ & 40.030 & 41.530 & 10 & Ms & 6.1 & Pasinler-Erzurum \\
\hline
\end{tabular}




\section{Tektonik ve Jeoloji}

Erzurum, kuzeyden Dumludağı (3169 m), kuzeydoğudan Kargapazarı Dağları (3120 m), güneyden ise Palandöken Dağları (3176m) tarafından çevrelenen tektonik bir oluşumdur. Bu dağların birçoğu volkanik kökenli olup daha sonra tektonik olaylara maruz kalarak oluşmuşlardır (Keskin vd. 1998 ve Yarbaşı vd. 2004). Bu tektonik olaylar; Arap plakasının Kuzey’e, Afrika plakasının Kuzeydoğuya, Avrasya plakasının ise Güney yöndeki hareketi Anadolu levhasının doğusunu sıkıştırmaktadır. Bu bağıl hareketler sonucu Kuzey Anadolu Fay Zonu (KAFZ) ve Doğu Anadolu Fay Zonu (DAFZ) oluşmuştur. Yine bu tektonik olaylar ile gelişen birçok mikro çatlak Erzurum ve çevresinin tektoniğini yönetmektedir. Bu fayların başında; sol yönlü doğrultu atımlı Erzurum-Dumlu Fay Zonu (EDFZ), sol yanal atımlı ters faylardan oluşan Palandöken Fay Zonu (PFZ), Başköy-Kandilli Fay Zonu (BKFZ) ve sol yönlü doğrultu atımlı fayı Aşkale Fay Zonu (AFZ) gelmektedir (Koçyiğit ve Canoğlu, 2017). Şehrin Batısında Karasal kırıntılılar, Güney Batısında Andezitler, Güneyde Palandöken dağının kapladığı alanda Ofiyolitik Melanj, Kuzey ve Kuzey Batıda Volkanitler ile çevrilidir (Şekil 4) (Ozer, 2019a).
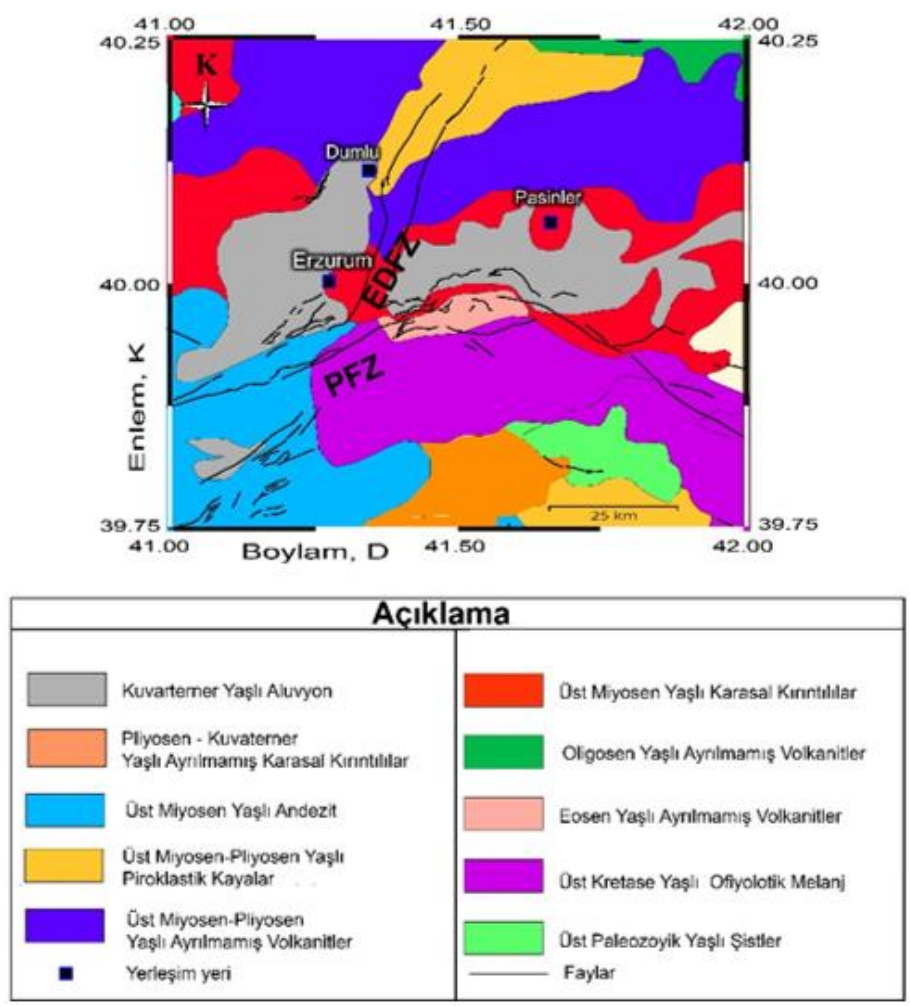

Şekil 4. Erzurum ve çevresinin basitleştirilmiş jeolojik ve tektonik birimler (Akbaş vd. 2013, Emre vd. 2013 ve Emre vd. 2018). EDFZ: Erzurum-Dumlu Fay Zonu, PFZ: Palandöken Fay Zonu

\section{Yöntem}

Sistematik olarak deprem verileri ilk etapta Linux tabanlı iş istasyonlarında SEISAN algoritması (Havskov ve Ottemoller, 1999) altında kataloglanmaktadır. Sonrasında her istasyona ait 3 bileşenli deprem kayıtlarında düşey bileşenlerde P- fazı, K-G ve D-B bileşenlerde S-fazı manuel olarak sismoloji alanında uzman personel tarafından tespit edilmektedir. Böylelikle deprem konumlamaları ilk etapta bu bilgiler ile gerçekleştirilebilecek hale getirilmektedir. D-B veya K-G bileşenlerdeki genliklerinden $\left(\mathrm{M}_{\mathrm{L}}\right)$ ve düşey bileşendeki depremin başlangıç ve bitiş noktalarının tespiti $\left(\mathrm{M}_{\mathrm{C}}\right)$ ile de klasik magnitud hesaplamaları her deprem için standart olarak yapılmaktadır. Sonrasında düşey bileşen kayıtlarında, deprem sinyalinin ilk hareketi baz alınarak kompresyon ve dilatasyonlar belirlenmekte ve odak mekanizma çözümleri yapılmaktadır. Böylelikle, deprem aktivitesinin hangi tür faylar aracılığıyla oluştuğu, eğim atım- doğrultu atım bileşenleri ile tektonik birimlerin hakim doğrultuları ve birbirleri ile ilişkileri hesaplanmaktadır. Deprem lokasyonları, ilk olarak Hypo71 yazılımı (Lee vd., 1972) ile gerçekleştirilmektedir. Tomografik hesaplamalarda mevcut konumların doğruluğunu kontrol etmek ve iyileştirmek için HYPOCENTER (Lienert vd., 1986; Lienert, 1991; Lienert ve Havskov, 1995), 
HYPOINVERSE (Klein, 2014), HYPODD (Waldhauser, 2001; Waldhauser ve Ellsworth, 2002) gibi algoritmalardan yararlanılmaktadır. Odak mekanizması çözümlerinde SEISAN altında çalışan FOCMEC (Snoke vd., 1984) ve P- dalgası ilk hareket yönünü dikkate alarak analiz yapan FPFIT (Reasenberg ve Oppenheimer, 1985) algoritmaları kullanılmaktadır. Ayrıca ihtiyaç halinde yine SEISAN ile birlikte çalışabilen PINV (Suetsugu, 1998) ve HASH (Hardebeck ve Shearer 2002, 2003) gibi yazılımlardan yararlanılmaktadır. Böylelikle ATA-DAM' da analiz edilen her olay; enlem, boylam, derinlik, magnitüd ve odak mekanizma çözümleri için hazır hale getirilmektedir. İleri düzey akademik çalışmalar için ise ATA-DAM; bu rutin analizler dışında kaynak parametreleri, bir boyutlu sismik hız yapısı, tomografik hesaplamalar, deprem tehlike analizleri, zemin büyütmeleri, Coulomb stres değişimleri ve azalım ilişkileri gibi konularda çalışma yürütebilecek teknik ve bilimsel altyapıya sahiptir.

\section{Bulgular ve Tartışma}

Bu çalışma kapsamında Doğu Anadolu Bölgesinde meydana gelen ve ATANET ağında 2014-2015 yılları arasında kaydedilen 660 'dan fazla deprem verisi analiz edilmiştir. Bu veri seti kullanılarak depremlerin lokasyonları (enlem, boylam ve derinlik) belirlenmiştir. Lokasyonu yapılan bütün depremlerin RMS hata oranı 0.5'den küçük değerdedir (Şekil 5). Erzurum bölgesinde 2014-2015 yılları arasında meydana gelen depremlerin birçoğunun odak derinlikleri ise $25 \mathrm{~km}$ 'den düşüktür. Depremlerin büyük bir yoğunlukta Aşkale fayında ve Horasan-Şenkaya Fay zonunda kümelendiği gözlemlenmiştir (Şekil 6). 2014-2015 yılları arasında kayıt edilen 668 deprem içinden 10 adet deprem seçilerek odak mekanizma çözümleri yapılmıştır (Çizelge 4). Odak mekanizması çözümleri incelendiğinde normal, ters ve doğrultu atımlı fayları temsil eden bulgulara ulaşılmıştır (Şekil 7). Fay düzlemi çcözümlerinde esas fay düzlemi; sismik etkinlik, fay çizgiselliği gibi hususlar dikkate alarak seçilmiştir. Erzurum ve çevresindeki odak mekanizma çözümleri bölgedeki doğrultu atım bileşeni baskın fayların hakim olduğunu, Van gölü ve çevresinde ise ters fayların etkisi altında olduğunu göstermektedir. KAFZ ve DAFZ'nun kesişim noktasında bulunan Karlıva ve çevresindeki çözümler, ters ve doğrultu atım bileşenleri hakim olan faylar tarafindan bölgenin tektoniği yönetildiğini göstermektedir (Çizelge 5). Elde edilen çözümler, sıkışma tektoniği rejimi etkisi altındaki Doğu Anadolu Bölgesindeki bilinen tektonik yapıyı desteklemektedir. Fay düzlemi sonuçları analizleri halen ATA-DAM'da devam etmekte olup, yeteri sayıda çözüme ulaşıldığında elde edilen veriler ışığında bölgenin tektonik özelliklerinin daha iyi anlaşılması için Gerilme Tensörü Analizleri yapılacaktır.

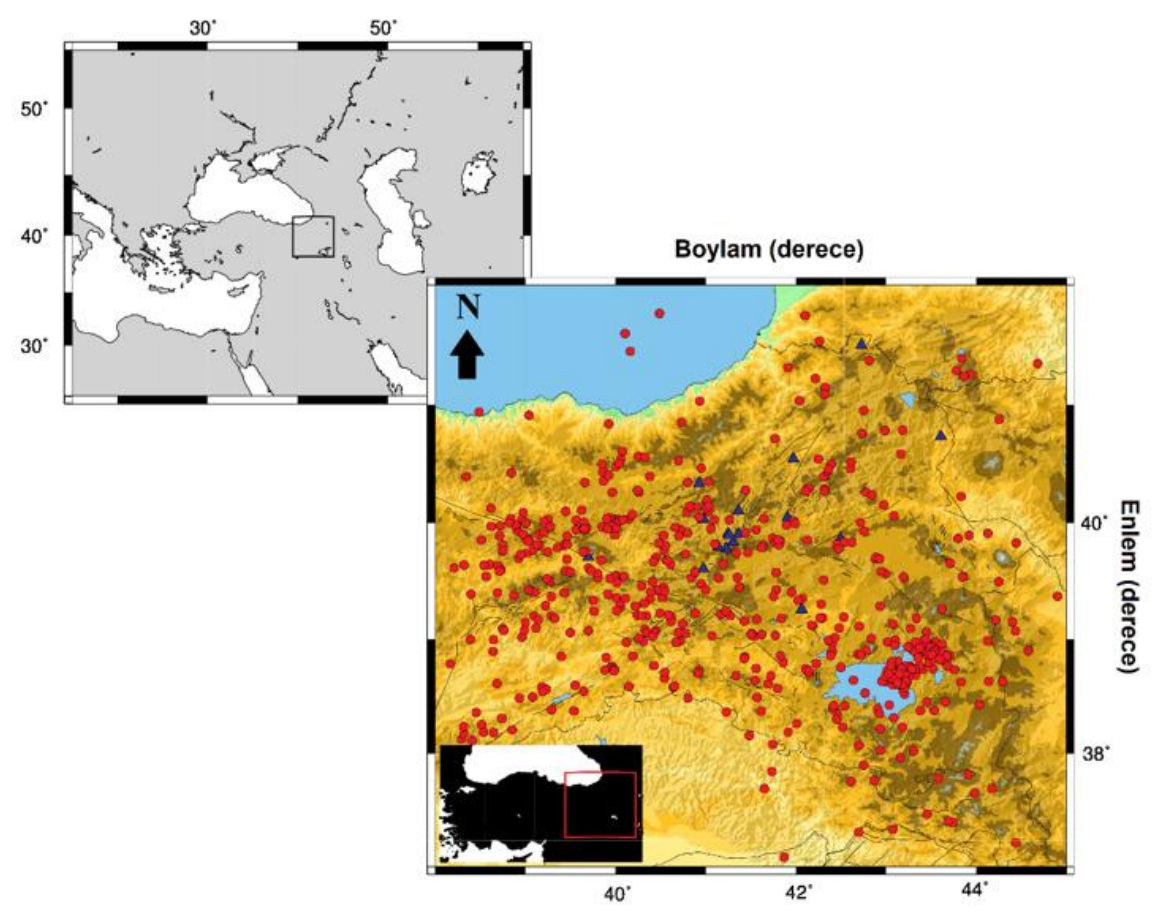

Şekil 5. 2014 - 2015 tarihleri arasında ATANET tarafindan kayıt edilen ve analizleri tamamlanan 668 depremin lokasyon dağıllımı 


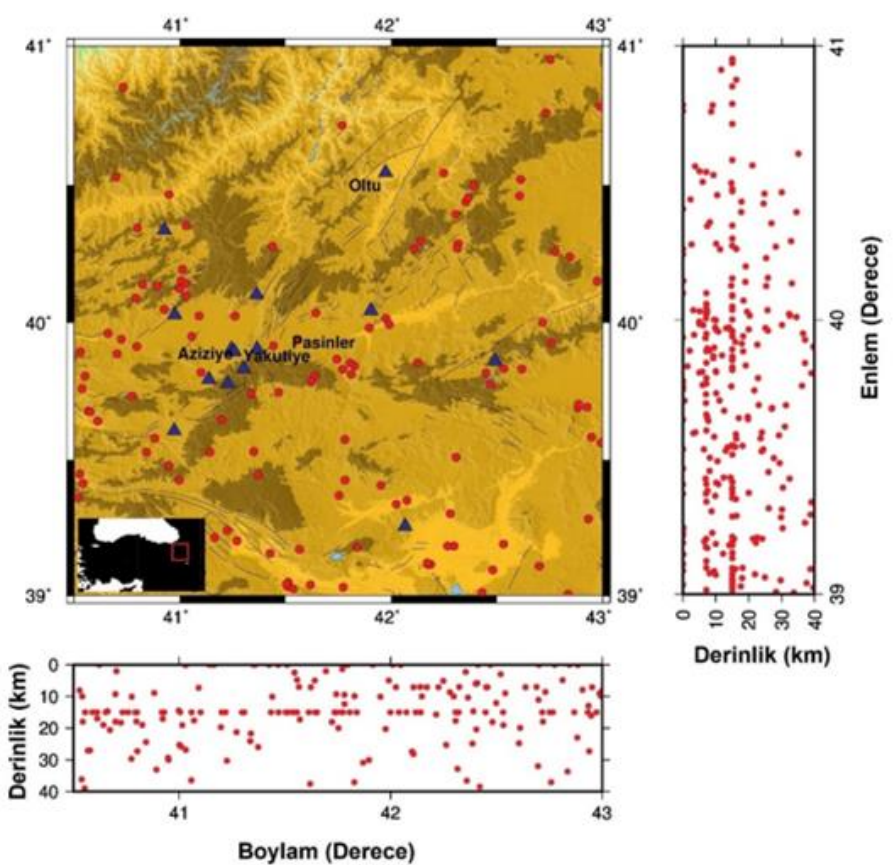

Şekil 6. 2014 - 2015 tarihleri arasında ATANET tarafından Erzurum ve çevresinde kayıt edilen ve analizleri tamamlanan depremlerin lokasyon dağılımı

Çizelge 4. 2014 -2015 tarihleri arasında ATANET ağından elde edilen 10 adet depremin (2.9 $\leq$ ML $\leq 4.0)$ odak mekanizması çözüm parametreleri

\begin{tabular}{|c|c|c|c|c|c|c|c|}
\hline No & Enlem( $\left(^{(}\right)$ & Boylam $\left({ }^{(}\right)$ & Derinlik & $\mathbf{M}_{\mathbf{L}}$ & Doğrultu $\left({ }^{(}\right)$ & Dalım $\left({ }^{\circ}\right)$ & Kayma $\left({ }^{\circ}\right)$ \\
\hline $\mathbf{1}$ & 40.12 & 40.75 & 7 & 3.2 & 234 & 74 & -12 \\
\hline $\mathbf{2}$ & 39.82 & 41.46 & 10 & 3.5 & 319 & 65 & -175 \\
\hline $\mathbf{3}$ & 40.42 & 42.21 & 12 & 3.1 & 285 & 84 & 177 \\
\hline $\mathbf{4}$ & 39.61 & 42.18 & 8 & 2.9 & 330 & 65 & 164 \\
\hline $\mathbf{5}$ & 39.05 & 43.62 & 10 & 3.7 & 80 & 45 & 98 \\
\hline $\mathbf{6}$ & 38.21 & 43.17 & 9 & 4.0 & 100 & 35 & 125 \\
\hline $\mathbf{7}$ & 39.24 & 41.72 & 6 & 3.6 & 265 & 70 & 180 \\
\hline $\mathbf{8}$ & 39.19 & 41.30 & 8 & 2.8 & 325 & 64 & 170 \\
\hline $\mathbf{9}$ & 38.91 & 39.64 & 5 & 3.3 & 241 & 79 & -8 \\
\hline $\mathbf{1 0}$ & 39.37 & 40.69 & 7 & 3.1 & 227 & 39 & 98 \\
\hline
\end{tabular}


Çizelge 5. Odak mekanizması çözüm yorumları

\begin{tabular}{|c|l|}
\hline $\begin{array}{c}\text { Deprem } \\
\text { No }\end{array}$ & \multicolumn{1}{c|}{ Yorum } \\
\hline 1 & Normal atım bileşeni olan baskın sol yönlü doğrultu atımlı fay \\
\hline 2 & Normal atım bileşeni olan baskın sol yönlü doğrultu atımlı fay \\
\hline 3 & Baskın sol yönlü doğrultu atımlı fay \\
\hline 4 & Ters atım bileşeni olan baskın sağ yönlü doğrultu atımlı fay \\
\hline 5 & Ters fay \\
\hline 6 & Doğrultu atım bileşeni olan baskın ters fay \\
\hline 7 & Ters atım bileşeni olan baskın sağ yönlü doğrultu atımlı fay \\
\hline 8 & Ters atım bileşeni olan baskın sağ yönlü doğrultu atımlı fay \\
\hline 9 & Normal atım bileşeni olan baskın sol yönlü doğrultu atımlı fay \\
\hline 10 & Ters fay \\
\hline
\end{tabular}

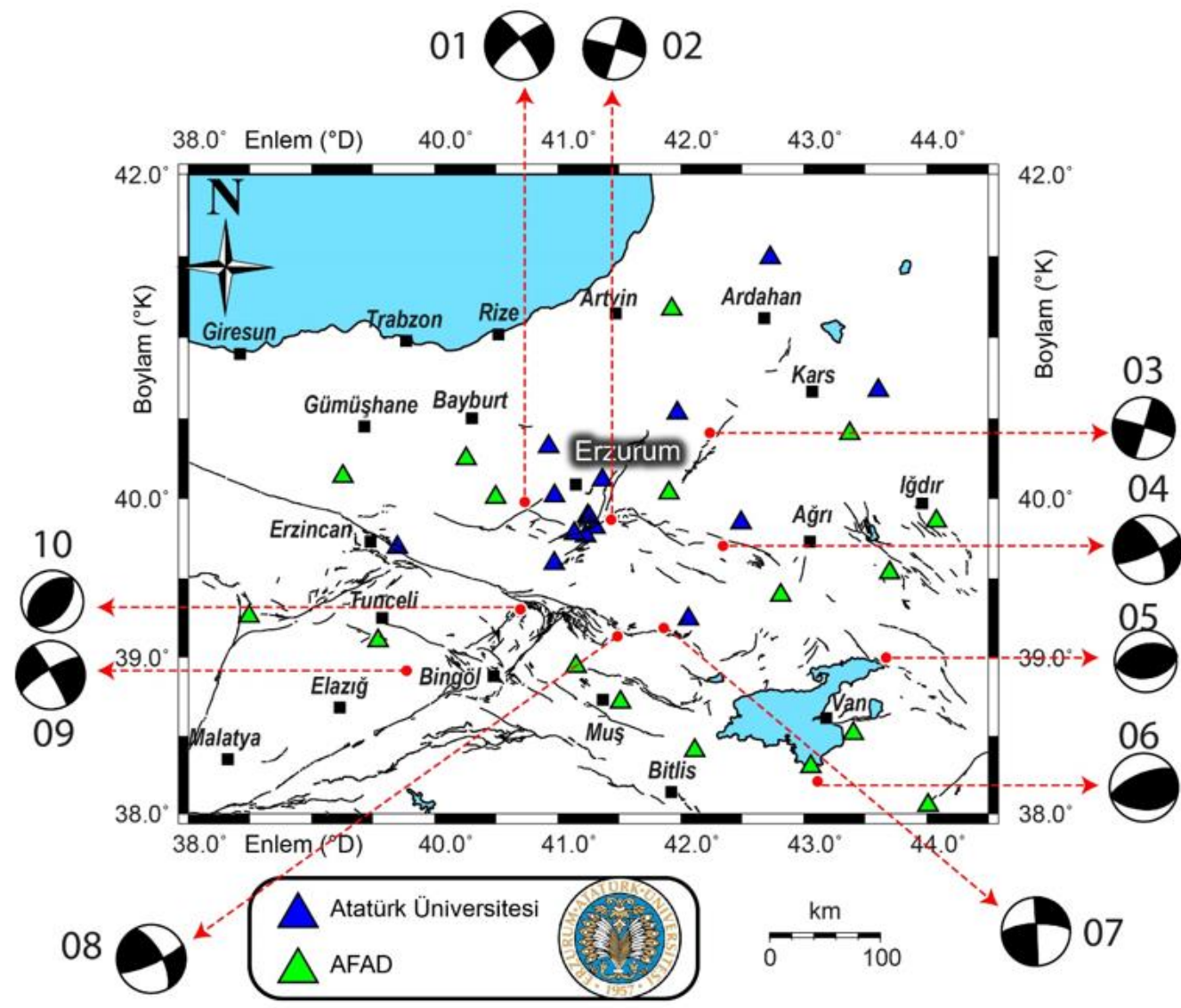

Şekil 7. ATANET deprem kayıtlarından yararlanarak yapılan 10 adet depremin odak mekanizması çözümleri. Mekanizma üzerindeki numaralar Çizelge 4 ve 5'de sunulmuştur. Fay bilgileri Maden Tetkik ve Arama (MTA) çizim editöründen sayısallaştırılmıştır (Emre vd. 2013 ve Emre vd. 2018).

\section{Sonuçlar}

Bu çalışmada, ATANET tarafından 2014-2015 yılları arasında kayıt edilen RMS hata değeri 0.5'den küçük 668 deprem analiz edilmiştir. Değerlendirilen depremlerin birçoğunun odak derinlikleri ise 25 km’den düşüktür. Depremlerin birçoğunun, Aşkale fayında ve Horasan-Şenkaya Fay zonunda kümelendiği gözlemlenmiştir. Magnitudu 3'den büyük ve tüm deprem istasyonlarında kayıt edilen 10 adet deprem seçilmiş ve odak mekanizma çözümlemeleri ile bölgenin sismotektonik özellikleri 
irdelenmiştir. Elde edilen sonuçlar bölgenin özellikle baskın doğrultu atım bileşeni olan faylar tarafından domine edildiği gözlenmiştir. Van gölü ve çevresinin ters fayların etkisi altında olduğu, KAFZ ve DAFZ' nun kesişim noktasında bulunan Karlıvva ve çevresindeki çözümler de, ters ve doğrultu atım bileşenleri hakim olan faylar tarafindan bölgenin tektoniğinin yönetildiği göstermektedir. Elde edilen çözümler, sıkışma tektoniği rejimi etkisi altındaki Doğu Anadolu Bölgesindeki bilinen tektonik yapıyı desteklemektedir.

\section{Teşekkürler}

Yazarlar deprem istasyonlarn kurulumunda büyük emeğgi olan Mehmet Salih Bayraktutan ve Mehmet Özyazıcı̆glu'na, istasyonların işletilmesi sirasında kesintisiz desteklerini esirgemeyen Afet ve Acil Durum Yönetimi Deprem Dairesi Başkanlığı personeline ve Atatürk Üniversitesi Deprem Araştırma Merkezi çalışanlarına teşekkür eder. Şekillerin bazıları GMT (Wessel vd. 2013) algoritması kullanılarak hazırlanmıştır. Deprem faz okumaları ve kataloglama işlemleri SEISAN programı (Havskov ve Ottemoller, 1999) yardımıyla gerçekleștirilmişstir. Veri transferi ve analizlerinde SeisComP yazılımından (https://www.seiscomp3.org/) yararlanılmıştır. Bu araştırmaya veri desteği, T.C. Başbakanlık Afet ve Acil Durum Yönetimi (AFAD) Deprem Dairesi Başkanlığı ve Atatürk Üniversitesi Deprem Araştırma Merkezi (ATA-DAM) tarafindan sağlanmıştır. Çalışma alanındaki tektonik birimler MTA Diri Fay haritasından (Emre vd. 2013 ve Emre vd. 2018) saylsallaştırlmıştır. Jeolojik birimler MTA Çizin editörü (http://yerbilimleri.mta.gov.tr/) ile sayısallaş̧tırılmıştır. Bu çalı̧̧ma Atatürk Üniversitesi Bilimsel Araştırma Projeleri Koordinasyon Birimince Desteklenmiştir. Proje Numarası: FAD-2019-7180.

\section{KAYNAKLAR}

AFAD Deprem Raporu, (2018). 30 Ekim 1983 Şenkaya/Erzurum-Sarıkamış/Kars depremi. Available: https://deprem.afad.gov.tr/tarihteBuAy?id=40 (July 2, 2019)

AFAD Deprem Daire Başkanlı̆̆ı. Available: https://deprem.afad.gov.tr/ (July 2, 2019)

Akbas, B., Akdeniz, N., Aksay, A., Altun, I., Balci, V., Bilginer E., et al. 2013. Turkey Geological Map, General Directorate of Mineral Research and Exploration, Ankara-Turkey. http://yerbilimleri.mta.gov.tr (July 2, 2019).

Barka, A. (1996). Slip distribution along the North Anatolian fault associated with the large earthquakes of the period 1939 to 1967. Bulletin of the Seismological Society of America, 86 (5), $1238-1254$

Bayrak, E., Yılmaz, S.., Softa, M., Türker, T., Bayrak, Y. (2015). Earthquake hazard analysis for East Anatolian Fault Zone, Turkey. Natural Hazards, 76 (2), 1063-1077.

Bayrak, Y., Yadav, R.B.S., Kalafat, D., Tsapanos, T.M. et al. (2013). Seismogenesis and earthquake triggering during the Van (Turkey) 2011 seismic sequence. Tectonophysics, 601, 163-176.

Bayrak E, 2019, Earthquake Hazard Analysis for Erzurum, 4. International Conference on Civil and Enviromental Geology and Mining Engineering, 20-22 Nisan 2019, Trabzon, Turkey.

Elliott, J.R., Copley, A.C., Holley, R., Scharer, K., Parsons, B. (2013). The 2011 Mw 7.1 Van (Eastern Turkey) earthquake. Journal of Geophysical Research: Solid Earth., 118 (4), 1619-1637.

Emre, O., Duman, T. Y., Ozalp, S., Elmaci, H., Olgun, S., Saroglu, F. (2013). 1/1.250.000 scaled Turkey active fault map, General Directorate of Mineral Research and Exploration special publication. Available: http://www.mta.gov.tr/ (July 2, 2019)

Emre, O., Duman, T. Y., Ozalp, S., Saroglu, F., Olgun, S., Elmaci, H. et al. (2018). Active fault database of Turkey. Bulletin of Earthquake Engineering, 16, 3229-3275.

Fichtner, A., Saygin, E., Taymaz, T., Cupillard, P., Capdeville, Y., Trampert, J. (2013). The deep structure of the North Anatolian Fault Zone. Earth and Planetary Science Letters, 373, 109-117.

45 I P a g e

www.iiste.org 
Hardebeck, J. L. and Shearer, P. M. (2002). A new method for determining estimation focal mechanisms. Bulletin of the Seismological Society of America, 92, 2264-2276.

Hardebeck, J. L. and Shearer, P. M. (2003). Using S/P Amplitude Ratios to Constrain the Focal Mechanisms of Small Earthquakes. Bulletin of the Seismological Society of America, 93, 24342444.

Havskov, J. and Ottemoller, L. (1999). SeisAn Earthquake analysis software, Seismological Research Letters, 70. Available: http://www.seismosoc.org/publications/SRL/SRL_70/srl_70-5_es.html (July 2, 2019)

Havskov, J., Sorensen, M.B., Vales, D., Ozyazicioglu, M., Sanchez, G., Li, B. (2016). Coda Q in Different Tectonic Areas, Influence of Processing Parameters, Bulletin of the Seismological Society of America, 106 (3): 956-970.

Keskin, M., Pearce J.A, Mitchell, J.G. (1998). Volcano-Stratigraphy and Geochemistry of CollisionRelated Volcanism on the Erzurum-Kars Plateau, Northeastern Turkey, Journal of Volcanology and Geothermal Research, 85, 1-4, 355-404.

Klein, F. W. (2014). User's Guide to HYPOINVERSE-2000, a Fortran Program to Solve for Earthquake Locations and Magnitudes. Open File Report 02-171, USGS.

Koçyiğit, A. ve Canoğlu, M.C. (2017). Neotectonics and Seismicity of Erzurum Pull-apart Basin, East Turkey, Russian Geology and Geophysics, 58, 99-122.

Lee, W. H. K., Bennett, R. E., Meagher, L. (1972). A method for estimating magnitude of local earthquakes from signal duration. Open le report, USGS.

Lienert, B. R. E., Berg, E., Frazer, L. N. (1986). Hypocenter: An earthquake location method using centered, scaled, and adaptively least squares. Bulletin of the Seismological Society of America, $76: 771-783$

Lienert, B. R. E. (1991). Report on modications made to Hypocenter. Technical report, Institute of Solid Earth Physics, University of Bergen, Bergen, Norway.

Lienert, B. R. E. and Havskov, J. (1995). HYPOCENTER 3.2: A computer program for locating earthquakes locally, regionally and globally. Seismological Research Letters, 66 (5), 26-36. https://doi.org/10.1785/gssrl.66.5.26.

McQuarrie, N., Stock, J.M., Verdel, C., Wernicke, B.P. 2003. Cenozoic evolution of Neotethys and implications for the causes of plate motions. Geophysical Research Letters, 30 (20), doi:10.1029/2003GL017992.

Orgulu, G., Aktar, M., Türkelli, N., Sandvol, E., Barazangi, M. (2003). Contribution to the seismotectonics of eastern Turkey from moderate and small size events. Geophysical Research Letters, 30(24), doi:10.1029/2003GL018258.

Ozer, C. (2019a). Investigation of the Local Soil Effects of Erzurum and Its Surroundings Using SSR and HVSR Methods. Dokuz Eylul University faculty of engineering journal of science and engineering, 21(61), 247-257.

Ozer, C. (2019b). Investigation of Soil Amplification in Lake Van Basin. Research reviews in engineering (Book Chapter), ISSN: 978-605-7631-38-1.

Ozer, C. and Ozyazicioglu, M. The Local Earthquake Tomography of Erzurum (Turkey) Geothermal Area, Earth Sciences Research Journal, accepted. 
Ozer, C., Ozyazicioglu, M., Gok, E., Polat, O. (2019). Imaging the Crustal Structure Throughout the East Anatolian Fault Zone, Turkey, by Local Earthquake Tomography. Pure and Applied Geophysics, 176 (6), 2235-2261.

Reasenberg, P. and Oppenheimer, D. (1985). FPFIT, FPPLOT and FPPAGE; Fortran computer programs for calculating and displaying earthquake fault-plane solutions. Technical report, U.S. Geol. Survey

Sengor, A. M. C. (1979). The North Anatolian transform fault: its age, offset and tectonic significance. Journal of the Geological Society, 136, 269-282, https://doi.org/10.1144/gsigs.136.3.0269.

SeisComP software. (https://www.seiscomp3.org/)

Simao, N. M., Nalbant, S. S., Sunbul, F., Mutlu, A. K. (2016). Central and eastern Anatolian crustal deformation rate and velocity fields derived from GPS and earthquake data. Earth and Planetary Science Letters, 433, 89-98.

Snoke, J. A., Munsey, J. W., Teague, A. G., Bollinger, G. A. (1984). A program for focal mechanism determination by combined use of polarity and SV-P amplitude ratio data. Earthquake notes, 55.

Suetsugu, D. (1998). Practice on source mechanism, IISEE lecture note. Technical report, Tsukuba, Japan.

Vanacore, E.A., Taymaz, T., Saygin, E. 2013. Moho structure of the Anatolian Plate from receiver function analysis. Geophysical Journal International, 193, 1, 329-337, https://doi.org/10.1093/gji/ggs107.

Waldhauser, F. (2001). HypoDD-A Program to Compute Double-Difference Hypocenter Locations. Technical report, U.S. Geol. Survey, Menlo Park, CA.

Waldhauser, F. and Ellsworth, W. L. (2002). Fault structure and mechanics of the Hayward Fault, California from double-difference earthquake locations. Journal of Geophysical Research B: Solid Earth, 107.

Wessel, P., Smith, W. H. F., Scharroo, R., Luis, J. F., Wobbe, F. (2013). Generic Mapping Tools: Improved version released. EOS, Transactions American Geophysical Union, 94, 409-410.

Yarbaşı, N., Kadirov, A., Bayrakturan, M.S. (2004). Erzurum Şehir Merkezi Batı Kesimi Jeoteknik Haritasında Kullanılan Kriterlerin İstatistiksel Analizi, Pamukkale Üniversitesi Mühendislik Bilimleri Dergisi, 10(2), 211-219. 